\title{
Evaluate Workforce Perspective in Industrialised Building System
}

\section{Khor Soo-Cheen ${ }^{1}$, Tiang Wai-Yew ${ }^{1}$, Olanrewaju Ashola Abdullatef ${ }^{1}$, Wai Soon-Han ${ }^{2}$}

\author{
1 Department of Construction Management, Faculty of Engineering and Green Technology, \\ Universiti Tunku Abdul Rahman, Malaysia \\ ${ }^{2}$ Department of Environmental Engineering, Faculty of Engineering and Green Technology, \\ Universiti Tunku Abdul Rahman, Malaysia
}

khorsc@utar.edu.my; waiyew42@1utar.my; olanrewaju@utar.edu.my; waish@utar.edu.my

Tel: 0164453872

\begin{abstract}
The workforce is essential in the construction sector for the Industrialised Building System (IBS). Previous researchers often obtain data and opinions from the perspective of construction professionals and often neglect the labour workforce opinion. The research is to study the perspective of IBS by evaluating workforce performances factors to improve IBS performance amongst the workforces. The data collection amounts 60 targeted respondents. This study found a strong correlation between motivation, education, and workforce skill level, affecting productivity in implementing IBS. Eventually, the resolution proposes an improvement of the workforce's monetary incentive and academic level.

Keywords: Workforce; Industrialised Building System (IBS); Construction Industry; Malaysia

eISSN 2514-751X C2021. The Authors. Published for AMER ABRA cE-Bs by e-International Publishing House, Ltd., UK. This is an open access article under the CC BY-NC-ND license (http://creativecommons.org/licenses/by-nc$n d / 4.0 /)$. Peer-review under responsibility of AMER (Association of Malaysian Environment-Behaviour Researchers), ABRA (Association of Behavioural Researchers on Asians) and CE-Bs (Centre for Environment-Behaviour Studies), Faculty of Architecture, Planning \& Surveying, Universiti Teknologi MARA, Malaysia.
\end{abstract}




\subsection{Introduction}

Industrialised Building System (IBS) is an innovative construction technique manufactured off or on site in a controlled environment. Then assemble onsite for a rapid construction process, which significantly increases the construction process's productivity and quality. The Construction Industry Development Board (CIDB) has categorised five types of IBS, which comprise of: Precast Concrete Framing, Panel and Box Systems, Steel Formwork Systems, Prefabricated Timber Framing Systems, Steel Framing Systems and Blockwork Systems as an effort to boost productivity, quality and sustainability in the construction industry. However, the fact is that the IBS construction technique is often significantly influenced by workforces' performance. Today, Malaysia's construction industry predominately consists of foreign and low-skill workers (Masri, 2019). This study aims to understand the relationship of worker performances with the efficiency of IBS performance. The issues such as educational level, awareness of workers in IBS techniques, motivational level and the training availability amongst the construction worker (Chaturvedi et al., 2018) are the critical factors that have a significant impact on the implementation of IBS in the Malaysia construction industry. Henceforth, the correlation between labour factors and IBS appraisal performances are investigated. The significant factors that hinder the successful implementation of the IBS system are identified through the review of previous research of other scholars and the survey of construction professionals and general labour. Despite the claim that IBS can significantly reduce labour reliance in the construction industry, such an advantage still does not eliminate the limiting factors of the labour-dependent industry. Furthermore, such the heavy reliance on human labour in the industry, the labour factor often plays the most significant role in determining the performances of IBS. Thus, in this study, the factors limiting the continuous improvement of IBS and human factors limiting the IBS to achieve higher efficiency are identified. Strategies to combat such limiting factors hinder the IBS technique from achieving new heights.

\subsection{Problem Statement}

The advantages of IBS include: reduce the amount of labour workforce, providing a betterquality building, increasing the productivity of construction projects, reducing wastage of material, and increasing the sustainability of the construction industry. However, the implementation of IBS is yet capable of obtaining a comprehensive of its objective, while some circumstances even show negative results (Ali et al., 2018). Despite the promise of labour reduction in IBS implementation, the labour issue is still one of the major factors that significantly impacted the IBS implementation's success rate (Jensen et al., 2018). The Malaysian construction industry consists of foreign, low-skill, uneducated, and unmotivated workers (Ali et al., 2018). Thus, this research studies the effect of the labour issue that previous researchers have identified to have a clearer insight into which labour issue plays a more impactful role on the quality, productivity, and sustainability appraisal on the IBS. Furthermore, a solution shall develop by incorporating opinions and suggestions from construction industry players at various levels to ensure the IBS technology can achieve its intention philosophy. 


\subsection{Research gap}

As for the labour issue for IBS performances, the limitation is that the previous researcher often chooses to obtain data and opinion from the perspective of construction professionals such as Consultant, CIDB authorities, Construction educators and other professional players to provide insight into the labour issue in Malaysia (Kassim and Walid, 2013; Ahmad et al., 2017). However, the authors only obtaining an opinion from professional industry players may cause the data of study to be biased significantly in this study, which regards the labour issue whom the labour itself is the main focus of the study. Thus, in this research, to significantly reduce the probability of bias in data collection and avoid untruth assumptions on labour behaviour, the respondents are from construction professionals and general construction labour.

\subsection{Aim and objective}

To study the perspective of IBS by evaluating workforce performances factors with the aim of improving IBS performance amongst the workforces. The objective of this research is such as:

a) To investigate the implication of workforce factors that affect the efficiency of the IBS performance.

b) To determine strategies to improve the IBS performances by developing workforces in the industry.

c) To establish the correlation between the workforce factors and strategies for improving the efficiency of the IBS performance.

\subsection{Sustainability issue}

The United Nations (UN) stated in the year 2015 of the United Nations Sustainable Development Goal (SDG), goal number Eight includes decent work and economic growth. The prioritisation of labour during the development of a national economy significantly reduces forced labour, human trafficking, and a low productive workforce. These issues can be undertaken through technology innovation and high productivity workforce cultivation (United Nations, 2015).

This study develops with an additional objective to fulfil the goal of the United Nations to identify the hindrances factors that are plaguing the construction industry workforce to reach its full potential. The further development of the strategy to resolve such issues supports the United Nations Sustainable Development Goal No.8 to create a highly productive workforce with a decent work environment for all workforce by 2030.

\subsection{Literature Review}

The performance of the IBS limits significantly because a specific amount of well-education and well-skilled workers are often required to succeed in any IBS project (Mohsen et al., 2019). The literacy of English languages is crucial during the implementation of IBS, as various crucial instructions and procedures shall be understood by the workforce when 
conducting an IBS project to ensure the system can achieve its efficiency and productivity (Ali et al., 2018). There are strong theoretical reasons for the positive monotonic relationship between education and productivity regarding higher economic growth rates. The case can support the Cobb-Douglas production function, result manifested each increment level of education worker to have an increment in productivity rate (Husain and Islam, 2016).

The study found that workers with tertiary education are more productive than those with secondary schooling. Workers with secondary education are more productive than those with primary education, and workers with primary education are more productive than those without formal education (Kampelmann et al., 2018). However, the education distribution among local and foreign workforces in Malaysia does not show a promising sign. In terms of the Malaysian workforce, the majority of the educational attainment of the workforce is "No formal education" and "Lower Secondary education". Meanwhile, in the foreign worker education distribution, a grim result showed that most foreign workers have received "No formal education", and a myriad of workforce received "Lower Secondary" or any higher form of education (Jordaan, 2018).

The complexity of the IBS modular requires commitment from the workforce to ensure its success rate. Any discontent and an unsatisfied worker may lead to a poor result. The workers involved in the construction sector considered their work as a "Job" rather than a career (National Insulation Association, 2019). It has been agreed that worker motivation and satisfaction drive higher productivity in construction firms (Aghayeva and Ślusarczyk, 2019). The motivational factors in terms of monetary incentive, work satisfaction, or achievement motivation helped enhance IBS adoption (Yunus et al., 2016). Motivation plays a crucial role in ensuring workers can provide sufficient dedication to implementing IBS. The success or failure of the IBS system often depends on the motivational and dedication factor of the workforce who are carrying out the IBS construction technique. Similar research advocated the strong evidential link between human happiness and human productivity with an average of $37 \%$ increment in productivity rate (Oswald et al., 2015). The complex IBS modular required a significant amount of dedication and commitment from the workforce to ensure its success rate, as any discontent and the unsatisfied worker may lead to a poor result than the anticipated performances of the IBS. Thus, establishing the significant relationship between job satisfaction and worker productivity, whereas such factors play a critical role in identifying the limitation of worker force productivity, especially in the construction industry.

Unlike the conventional construction method, IBS modular often requires extensive knowledge, experience and skill during its implementation. Thus, the availability of expertise and skilled workers is a significant factor in implementing the IBS modular. The labour productivity in implementing IBS modular can improve by increasing the skills and experience of the workforce (Wuni et al., 2021). However, most semi-skilled and unskilled workers have dominated Malaysia's labour market (Department of Statistics Malaysia, 2020). Moreover, the domination of foreign workers categorised as low-skilled workers in the construction industry worsens the situation. There are significant differences between local and foreign workers regarding their competency and capability (Salleh et al., 2020). Most employers in Malaysia's company consider underinvesting in the commitment to provide training for their workers 
(International Labour Organization, 2016). This leads the younger generation to be reluctant to join the construction industry to replenish the ageing workforce (Muth, 2019). Only approximately $30 \%$ of labour have been provided professional training courses by their Employer (Kassim and Walid, 2013). The lack of skills development training causes the labour not to see many opportunities for career progression, making the construction industry unattractive (Zaki et al., 2012). Thus, significantly lowering the availability of skilled labour in the construction industry affects the productivity and implementation of IBS.

The awareness of IBS modular in Malaysia is significantly low among qualified professionals (Public Work Department, Officer Contractor Association Malaysia, and Repository Development Officer). It has been found did not attend any introductory course or equivalent training to implement IBS. This scenario, coupled with the limited number of IBS manufacturing factories thinly scattered and distant, attributed to low awareness of IBS modular (Kassim and Walid, 2013). Severe knowledge deficiency among skilled workers, including designers, engineers, and others, still exists to this day has led to the project delay and request extra time to finish the task, which is also one hurdle in IBS implementation (Ahmad et al., 2017).

Following the persistent labour issue in the construction industry, which significantly affects the performances and implementation of IBS in the Malaysian construction industry, local and international researchers have proposed various innovative solutions. While some solutions show insignificantly result, specific solutions do show promising results when implemented in the construction industry to tackle the labour mentioned earlier issue in the construction industry. Further supported by researcher Bakotić (2015) concluded that job satisfaction more strongly determines organisational performance than organisational performance determines job satisfaction. According to Danica Bakotic (2015), her research is to understand the correlation between organisational performances and job satisfaction among workers. Studying the job satisfaction score of a worker in an organisation against the organisation's yearly return of equity (ROE), a strong positive coefficient correlation from 0.407 to 0.443 shows that workers with higher job satisfaction can provide better organisation performances and productivity. Thus, it is believed that by promoting higher satisfaction and happiness among the workforce regarding their job, higher productivity will be achieved.

An awareness of IBS will accelerate the project's overall performance, and IBS knowledge is necessary for all stakeholders (Ahmad et al., 2017). The authority's body shall increase its effort to raise awareness among the workforce in the construction industry to increase the rate of IBS implementation (Kassim and Walid, 2013). The loss of the local workforce and over-dependency on foreign workers is the major labour issue in the construction industry, which dramatically affects the construction industry's performance. A vital effort is required for a better investment in the workforce to enable them to stay attracted to their job and see a career progression. Thus, this will retain a significant portion of the local workforce to ensure a vast pool of workforce are available for the labour-intensive construction industry to ensure the industry stays highly competitive (Manap et al., 2017).

The official body involvement plays a significant role in promoting the involvement of construction labour in IBS implementation. This issue can be taking the initiative sort of 
monetary incentive, material promotion, CIBD levy exemption and a tax break for the construction company to improve the involvement and awareness of construction players (ElAbidi et al., 2019). The educational institute needs to further improve its syllabus and education curriculum to involve the IBS technologies to equip future construction professionals with sufficient knowledge to effectively carry out IBS implementation in the construction industry (Lat et al., 2021).

Undeniably, the Malaysian construction industry is still a labour-intensive industry requiring a vast workforce pool to support it. Despite the implementation of IBS, which promises a significant reduction of labour, the labour reduction benefit is fruitless if the labour issue is still persistent in the construction industry, which significantly affects the performances of IBS. Furthermore, Malaysian construction labour is not as perfect as we presume. This scenario is due to the domination of low-skilled foreign workers, poor education, lack of motivation among workers, the ageing workforce, and poor retention of the effort contributed to the construction industry. Those are a few significant issues that are still rampant throughout the industry, which is currently ravaging the performances and integrity of the construction industry. Thus, it is crucial to identify the various limitations and hindrances among labour during the implementation of IBS in Malaysia. As aforementioned, to root out such limitations or restrictions by diverse efforts such as promoting workforce retention, boosting job satisfaction, and raising workforce awareness. The industry should take a few vital steps to significantly improve the competitiveness and performance of the sector.

\subsection{Methodology}

The study is researched through data collection from the professional construction industry player with multiple years of experience in IBS to obtain the labour factor that limits the performances of IBS. Furthermore, simultaneous data collection will carry out toward the general worker in the construction industry. Both collected data are being used to verify the labour factor that affects IBS appraisal performances. The research employed questionnaire survey methods distributed to a dichotomous targeted population. The questionnaire comprised sections: Demographics; Educational level; Skill level in IBS; Motivational level in IBS technology; and Strategy Improvement of productivity. The sampling is non-probability and based on the convenience and judgement criteria for selecting construction professionals and general workers in Perak, Malaysia construction site involved in the IBS project as the study sample. The data obtained was analysed through Descriptive Analysis, Pearson Correlation, Reliability, Validity, which uses SPSS software.

\subsection{Results \& Discussion}

Out of 100 online survey questionnaires were distributed throughout construction sites. A $60 \%$ response rate was obtained; 30 numbers of the respondent are construction professionals, and another 30 numbers are general labours. $53 \%$ out of 30 construction professionals 
involved in more than five IBS projects. However, only $20 \%$ out of 30 general labours involve more than five IBS projects. The educational level of construction professionals is at least Tertiary Educated. However, most general labours have a lower educational level which ten are non-educated, and 12 are primary educated. The survey questionnaire is significant reliability and validity in terms of strength in internal consistency and is accurately measured for each part of the question, as shown in Table 1.

Table1:Results for reliability and validity

\begin{tabular}{|c|c|c|c|c|}
\hline $\begin{array}{c}\text { Section } \\
\text { Questionnaire }\end{array}$ & Cronbach's Alpha & $\begin{array}{c}\text { Strength of internal } \\
\text { consistency }\end{array}$ & KMO values & Sampling adequacy \\
\hline Educational & 0.957 & Excellent & 0.882 & Meritorious \\
\hline Skill & 0.979 & Excellent & 0.869 & Meritorious \\
\hline Motivational & 0.932 & Excellent & 0.867 & Meritorious \\
\hline Strategy & 0.948 & Excellent & 0.795 & Meritorious \\
\hline
\end{tabular}

Malaysia is a country consisting of various ethnicity, and the majority of the foreign construction labour are from various parts of the world. No common language is shared among each other in the industry. Thus, the language barrier is a significant issue that affects the IBS performances. It has been found that construction professionals are often at the top of an organisational hierarchy and the general labour at the bottom of an organisational hierarchy. These two groups might be difficult to carry out both Upward and Downward communication because both individuals cannot comprehend and understand each other because of the language barrier (Hee et al., 2019). The study had found that $80 \%$ of General Workers have "Poor" and "Limited Proficiency" in English usage.

On the contrary, $83.3 \%$ of Construction professionals have a "Competent Proficiency" and "Excellent Proficiency" in English usage. Furthermore, almost 53.3\% of the General workers show a "Poor" and "Below Average" Proficiency in Bahasa Malaysia usage. On the contrary, $66.7 \%$ of Construction professionals have an "Excellent Proficiency", and 33.3\% show a "Competent Proficiency" in language usage. There is a wide gap in language proficiency among these two groups. The effectiveness of Upward and Downward communication is unable to be carried up, thus resulting in poor performances on the IBS implementation as General workers are unable to comprehend the instruction provided by the Construction professional.

Although the early implementation of IBS in Malaysia started in 1960 (Abedi et al., 2011), a shockingly low level of understanding commonly exists among both construction players. A mean score of 3.47 was obtained among the 30 Construction professionals in understanding IBS modular. A more disappointing mean score of 2.2 was obtained among the 30 General Worker, which indicated a poor understanding of IBS modular. Such poor understanding is the common cause of poor performances of the IBS. Meanwhile, $60 \%$ of the Construction professionals and $56.7 \%$ of the General Worker agreed that they had not received sufficient training/education and experiences to qualify them for implementation of IBS. Such a finding further reinforces the poor education/training and experiences that hinder implementing IBS effectively. It has been observed that the higher the educational level of a construction 
individual, the higher their understanding of the IBS modular will be. The correlation of Construction professionals indicates a positive relationship between educational level and understanding of IBS with a Pearson Correlation score of 0.699 is significant at the 0.01 level. In contrast, the correlation of General workers indicates a high positive relationship between educational level and understanding of IBS with a Pearson Correlation score of 0.931 is significant at the 0.01 level, and vice versa.

The study has shown among 60 respondents that up to $52 \%$ of them are aged $41-50$ years old. They are categorised as old labour groups. Only $13 \%$ of them aged around $20-30$ years old. Such figures signify that fewer younger generations are joining the construction sector. Thus, with the ageing workforce and the reluctance of the younger generation to join the industry, the construction industry is slowly losing all its experienced, knowledgeable and skilful workforce, which will eventually lead to performance hindrance. The majority of the respondents (87\%) found unsatisfied with implementing IBS in their current and past projects. A strong Pearson Correlation score of -0.870 is significant at the 0.01 level was observed among the satisfaction and productivity of the IBS. Such phenomenal signify that as the unsatisfaction level increases in implementing the IBS process, the productivity and efficiency will decrease. This case has reinforced the theory of Oswald et al. (2015) that productivity significantly correlates to job satisfaction among the workforces.

Table 2 Demotivating factors

\begin{tabular}{|l|c|c|}
\hline & Mean & Std. Deviation \\
\hline Lack of incentive & 4.48 & 1.200 \\
\hline The employer did not provide the required training & 4.42 & 1.183 \\
\hline Lack of exposure during educational day curriculum & 4.32 & 1.295 \\
\hline Difficulty in finding proper training/knowledge channel & 4.30 & 1.266 \\
\hline Unable to afford training & 4.23 & 1.345 \\
\hline Lack of opportunity to attain IBS training/knowledge & 4.18 & 1.308 \\
\hline Lack of interest & 4.05 & 1.523 \\
\hline Lack of leadership & 3.98 & 1.228 \\
\hline Unaware of the existence of IBS modular & 3.75 & 1.569 \\
\hline
\end{tabular}

By referring to Table 2, the Lack of Incentive is the leading factor with the highest mean score of 4.48 caused demotivation of construction players to involve in IBS. In addition, the CIDB levy $(0.125 \%)$ for any IBS involvement project is often argued too insignificant to make any difference. All findings supported by Elmualim et al. (2018) that there is non-other significant effort conducted by the government or construction authority body to provide any incentive to construction individuals. The Unawareness of the IBS existence is the lowest mean score of 3.75. However, construction players' opportunity to expose IBS during their training/educational or working days is still rampant. It can be observed through variables of Lack of exposure during educational day curriculum, Difficulty finding proper training/knowledge channel, Inability to afford training, the employer not providing the required training, and Lack of opportunity to attain IBS training/knowledge. All these obtained a mean score of more than 4 , which indicated the lack of accessibility of knowledge and exposure to 
IBS modular, thus resulting in poor motivation for the industry player to be interested and pursue further involvement in the IBS modular.

Table 3 Strategies for Improvement in IBS implementation

\begin{tabular}{|l|c|c|}
\hline & Mean & Std. Deviation \\
\hline Government Incentive program & 4.73 & .899 \\
\hline $\begin{array}{l}\text { Encouragement from employer to provide or subsidy more IBS modular related } \\
\text { training }\end{array}$ & 4.67 & .968 \\
\hline Making IBS modular training more widely available in terms of access and cost & 4.53 & .982 \\
\hline Incorporation of IBS knowledge in the construction field of education syllabus & 4.42 & 1.225 \\
\hline Attract more young/new generation into the industry to replace the ageing labour & 4.07 & 1.376 \\
\hline Promote job satisfaction for construction labour during the implementation of IBS & 3.82 & 1.372 \\
\hline Mass media advertisement & 3.18 & 1.712 \\
\hline
\end{tabular}

By referring to Table 3, the first strategy to improve IBS implementation is Monetary incentive. This strategy is the most effective method to resolve the low productivity, including variables such as the Government incentive program; and Making IBS modular training more widely available in terms of access and cost, which have a mean score of 4.73 and 4.53 , respectively. Secondly, the Educational/Training improvement strategy is highly significant with variables comprising of Incorporation of IBS knowledge in student education syllabus; and Encouragement from Employer to provide or subsidy more IBS modular related training. Both have shown a mean score of 4.42 and 4.67 . Such a phenomenon is expected because the educational factor is significantly correlated with improving IBS implementation.

Next, the factor of improving awareness was the least significant among all the other factors. The only variable (Mass Media Advertisement) obtained a mean score of 3.18. Thus, explaining the respondents' opinion that mass media advertising promotes awareness among IBS is redundant. However, the variable Attract more young/new generation into the industry obtained a mean score of 4.07 . Perhaps such finding can be explained because the current construction industry reckons that more pressing factors such as Educational/training improvement and Monetary incentives shall resolve to increase the efficiency of the IBS implementation, which will eventually attract the younger generation to join the industry. The last strategy factor (Promote job satisfaction) scored 3.82, which is essential for workers to raise the productivity level of IBS implementation.

The strategies to improve workforce education to resolve the educational factor showed a strong positive relationship with a Pearson Correlation score of 0.672 to 0.950 is significant at the 0.01 level. The strategies to improve the workforce factor of low-skilled workforce domination through improved workforce educational/training, attracting new labour and making IBS training modular more widely available shown a strong positive relationship with a Pearson Correlation score of 0.800 to 0.999 is significant at the 0.01 level. The analysis indicates that the strategies to improve workforce efficiency from the issue of poor job motivation and satisfaction through the promotion of job satisfaction show a positive relationship with a Pearson Correlation score of 0.700 to 0.999 is significant at the 0.01 level. 
Eventually, the correlation analysis has manifested that the undertaken strategies enable the efficiency of IBS performance in terms of workforce factors.

\subsection{Conclusion}

It is concluded that the three primary factors have been established: Limitation of Educational/Training Factor; Low Job Motivation and Satisfaction; and Domination of LowSkilled Worker showing a significant relationship in effecting IBS performances among the Construction professional and General worker. The research unfolded various variables made up the limitation factor and debunked to rebuke or reinforce the theory established by the past researchers. Furthermore, upon identifying the root of the problem among construction workforces, various strategies established by past researchers are examined. In contrast, some strategies accept specific strategies that have shown little to no effect in improving the situation due to the ever-evolving situation. However, this study only examined one underlying issue affecting the IBS performances of the workforce in terms of labour factor. Nevertheless, the various underlying issues are yet to explore to understand the whole situation that is currently happening in the construction industry. Thus, to improve such performances, issue a broad scope of study which venture beyond the labour issue shall be conducted to obtain a clearer picture of the extended issue of IBS implementation.

\section{References}

Abedi, M., Fathi, M. S., \& Mirasa, A. K. (2011). Establishment and development of IBS in Malaysia. Sustainable Building and Infrastructure Systems: Our Future Today, 405.

Aghayeva, K., \& Ślusarczyk, B. (2019). Analytic hierarchy of motivating and demotivating factors affecting labour productivity in the construction industry: the case of Azerbaijan. Sustainability, 11(21), 5975.

Ahmad, M., Haseneshkorfu, O. O., \& Nigar, K. (2017). The barriers to the implementation of industrialised building systems (IBS) in high rise structures in Selangor. Int J Adv Mech Civ Eng, 4, 94-99.

Ali, M. M., Abas, N. H., Affandi, H. M., \& Abas, N. A. (2018). Factors impeding the industrialised building system (IBS) implementation of building construction in Malaysia. International Journal of Engineering and Technology (UAE), 7(4), 2209-2212.

Bakotić, D. (2016). Relationship between job satisfaction and organisational performance. Economic researchEkonomska istraživanja, 29(1), 118-130.

Chaturvedi, S., Thakkar, J. J., \& Shankar, R. (2018). Labour productivity in the construction industry: An evaluation framework for causal relationships. Benchmarking: An International Journal.

Department of Statistics Malaysia (2020). Labour Market Review Malaysia, Fourth Quarter 2020. Malaysian Bureau of Labour Statistics 
El-Abidi, K. M. A., Ofori, G., Zakaria, S. A. S., Mannan, M. A., \& Abas, N. F. (2019). Identifying and evaluating critical success factors for industrialised building systems implementation: Malaysia study. Arabian Journal for Science and Engineering, 44(10), 8761-8777.

Elmualim, A., Mostafa, S., Chileshe, N., \& Rameezdeen, R. (2018). Construction and the circular economy: smart and industrialised prefabrication. In Unmaking waste in production and consumption: Towards the circular economy. Emerald Publishing Limited.

Hee, O. C., Qin, D. A. H., Kowang, T. O., Husin, M. M., \& Ping, L. L. (2019). Exploring the impact of communication on employee performance. International Journal of Recent Technology and Engineering, 8(3), 654-658.

Husain, S., \& Islam, M. S. (2016). A test for the Cobb Douglas production function in the manufacturing sector: The case of Bangladesh. International Journal of Business and Economics Research, 5(5), 149-154.

International Labour Organization (2016). Non-Standard Employment Around the World. International Labour Office, Geneva.

Jensen, P. A., Maslesa, E., Berg, J. B., \& Thuesen, C. (2018). 10 questions concerning sustainable building renovation. Building and Environment, 143, 130-137.

Jordaan, J. A. (2018). Foreign workers and productivity in an emerging economy: The case of Malaysia. Review of Development Economics, 22(1), 148-173.

Kassim, U., \& Walid, L. (2013). Awareness of the Industrialized Building System (IBS) implementation in Northern Malaysia-A case study in Perlis. Procedia Engineering, 53, 58-63.

Kazaz, A., Manisali, E., \& Ulubeyli, S. (2008). Effect of basic motivational factors on construction workforce productivity in Turkey. Journal of civil engineering and management, 14(2), 95-106.

Kampelmann, S., Rycx, F., Saks, Y., \& Tojerow, I. (2018). Does education raise productivity and wages equally? The moderating role of age and gender. IZA Journal of Labor Economics, 7(1), 1-37.

Lat, D. C., Noor, S. M., Rahman, N. S. A., \& Razali, R. (2021, May). Construction industry towards IR 4.0-A review. In AIP Conference Proceedings (Vol. 2339, No. 1, p. 020084). AIP Publishing LLC.

Manap, N., Noh, N. M., \& Syahrom, N. (2017, December). Recruitment criteria and attraction strategies for local trained labour in Malaysia's construction industry. In IOP Conference Series: Earth and Environmental Science (Vol. 109, No. 1, p. 012011). IOP Publishing.

Masri,N.B. (2019). Industrialized Building System (IBS). The Problems and Strategies to Increase the Adoption of IBS in the Malaysian Private Sector. Thesis: Universiti Malaysia Pahang.

Mohsen, A., Yunus, R., Handan, R., Kasim, N., \& Hussain, K. (2019). Determining factors for enhanced skilled worker requirements in IBS construction projects in Malaysia. In IOP Conference series: earth and environmental science (Vol. 220, No. 1, p. 012048). IOP Publishing.

Muth, R. (2019). Why Many Young People Don't Want Careers in Construction. News, Blue Diamond Machinery, LLC.

National Insulation Association (2019). New Report Finds Labor Challenges Affecting Construction Project Deadlines. Insulation Outlook Magazine. 
Khor, S.C., et.al. / Asian Journal of Environment-Behaviour Studies (ajE-Bs), 6(19) May / Aug 2021 (pp.15-26)

Oswald, A. J., Proto, E., \& Sgroi, D. (2015). Happiness and productivity. Journal of labour economics, 33(4), 789822.

Rahman, A. B. A., \& Omar, W. (2006, September). Issues and challenges in the implementation of industrialised building systems in Malaysia. In Proceedings of the 6th Asia-Pacific Structural Engineering and Construction Conference (APSEC 2006) (pp. 5-6).

Salleh, N. M., Lop, N. S., Mamter, S., \& Abidin, Z. Z. (2020). Preliminary Survey on Availability of Local Skilled Construction Workers at Construction Sites. International Journal of Academic Research in Business and Social Sciences, 10(3), 618-632.

Wuni, I. Y., Shen, G. Q., \& Darko, A. (2021). Best practices for implementing industrialised construction projects: lessons from nine case studies. Construction Innovation.

Yunus, R., Suratkon, A., Wimala, M., Hamid, H. A., \& Noor, S. R. M. (2016). Motivational factors on adopting modular coordination concept in an industrialised building system (IBS). In MATEC Web of Conferences (Vol. 47, p. 04017). EDP Sciences.

United Nations (2015). United Nations Sustainable Development Goal (SDG) No.8: Promote sustained, inclusive and sustainable economic growth, full and productive employment and decent work for all. Department of Economic and Social Affairs Sustainable Development: New York, NY, USA.

Zaki, S., Mohamed, S., \& Yusof, Z. (2012). Construction skilled labour shortage-The challenges in the Malaysian construction sector. OIDA International Journal of Sustainable Development, 4(5), 99-108. 